\title{
Ontological and epistemological challenges of measuring the effectiveness of urban counterterrorism measures
}

\author{
Sissel H. Jore ${ }^{1}$ \\ Published online: 26 November 2019 \\ (c) The Author(s) 2019
}

\begin{abstract}
Cities and their citizens are increasingly seen as vulnerable targets for terrorist attacks, and nowadays city planners have become important actors in making decisions about urban security. Multiple urban counterterrorism measures that have affected the urban landscape have been implemented in recent years. Simultaneously, new legislation requires security measures to be effective. This article outlines and discusses the epistemological and ontological challenges of acquiring knowledge about the effectiveness of urban counterterrorism measures from a local city planner's perspective. This piece of work is a discussion paper based on a literature review. We conclude that, despite the knowledge limitations regarding the threat of urban terrorism and associated countermeasures, local planners should refrain from just uncritically implementing urban countermeasures without considering the effectiveness of such measures. Without knowledge on what constitutes the effectiveness of urban security measures, the city might end up infringing the same values that it aims to protect, without achieving security.
\end{abstract}

Keywords Effectiveness · Urban counterterrorism measures · Security

\section{Introduction}

Cities and their citizens are increasingly seen as suitable targets for terrorist attacks. In recent years, European cities have been the scene of an increase in terrorist attacks, predominately against civilians, using low-tech weapons such as knives, hand-held firearms, vehicles, or vehicle-borne explosives (Hemmingby 2017). Terrorist targets are no longer exclusively limited to the high profile, such as government buildings. Softer targets, such as crowded urban spaces, are also alleged to need protection. As a result, key security challenges in this new era focus on

Sissel H. Jore

sissel.h.jore@uis.no

1 Department of Safety, Economics and Planning, University of Stavanger, Stavanger, Norway 
everyday sites, public spaces, and gatherings of people (Graham 2012), making urban counterterrorism more complex and challenging than before.

Additionally, the requirements for what should substitute the basis of counterterrorism decisions have changed. Since 11 September 2001, counterterrorism has increasingly been viewed through the lens of the risk management culture that dominates contemporary society (Power 2004; Office, U. S. G. A. 2005), and risk analysis has been proposed as the recommended perspective for making decisions about the implementation of counterterrorism. This tendency to utilize risk-based approaches is mirrored in multiple laws and guidelines published in recent years. The commonality of such approaches is that they view terrorism as a manageable risk and deem it possible to acquire knowledge about the likelihood and the consequences of an attack, as well as to assess the risk-reducing effects of counterterrorism measures (Jore 2017). In Norway, the corollary of risk-based thinking is mirrored in a new National Security Law, in effect from 1 January 2019. The prerequisite behind this new law is that security measures should be based on the principle of economic profitability (National Security Law 2018) and that "Costs incurred by the statutory security measures must be in reasonable proportion to the security gains achieved by the measure" (NOU 2016, p. 18). The implication of this new law is that local authorities are now required not only to make cost estimates of security measures but also to assess the effectiveness of counterterrorism measures before implementation. The request to measure effectiveness also exists in multiple other guidelines that have been published in recent years (see for example NSM 2015). This article questions whether it is possible, from a local perspective, to assess the effectiveness of urban counterterrorism measures. Although the mitigation of terrorism through situational crime prevention is widespread in many countries (Clarke 2009; Coaffee 2010), the effectiveness of such measures is hardly ever discussed. This is also the case for counterterrorism in general; in their meta-analysis of the effectiveness of counterterrorism measures, Lum et al. (2006) discovered that out of 20,000 evaluated studies on terrorism, only seven contained information on the effectiveness of counterterrorism policies. They concluded that we currently know almost nothing about the effectiveness of any of these programs (Lum et al. 2006, p. 510). Moreover, studies that deal with the effectiveness of counterterrorism measures tend to analyse the effectiveness from a state or sector perspective, predominantly using quantitative data analysis to measure the effectiveness of counterterrorism measures (see for example Cauley and Im 1988; Enders and Sandier 1993). In their literature review of the effectiveness of counterterrorism measures, Van Um and Pisoiu (2015) found that the literature displays case and data selection biases and has produced contradictory results with regard to the effectiveness of measures. Scholars have also dealt with how to measure the cost of counterterrorism measures (see for example Akhtar et al. 2010; Stewart 2008; Stewart and Mueller 2013; Dillon et al. 2009), but in general these scholars do not problematize the concept of effectiveness. Consequently, the academic literature does not seem to answer the simple question: Is it really possible to measure the effectiveness of counterterrorism measures from a local planner's perspective?

The threat of terrorism that can strike at an almost endless number of locations entails major challenges for the various local agencies that are responsible for 
protecting people, assets and critical infrastructure from such threats. Thus, there is reason to ask whether it is really possible to measure the effectiveness of counterterrorism measures from a local perspective or whether there are certain characteristics of the threat of terrorism that make the prism of effectiveness a problematic one to apply. There might be inherent characteristics within the threat of terrorism and associated security measures that place limitations on the possibility of measuring the effectiveness of counterterrorism. The objective of this article is to outline and discuss the epistemological and ontological challenges involved in acquiring knowledge about the effectiveness of urban counterterrorism measures. When dealing with the effectiveness of urban counterterrorism measures, it is appropriate to ask: What is the phenomenon the city strives to protect itself from, and how do the characteristics of the phenomenon influence our ability to measure the effectiveness of urban counterterrorism measures? This piece of work is a discussion paper based on a literature review. We use urban counterterrorism in Norway as an example to illustrate these challenges. We conclude that the ontological and epistemological challenges of evaluating the effectiveness of security measures do not mean that the measurement of the effectiveness of urban security measures is impossible. The ontological and epistemological challenges should rather be seen as knowledge constraints that need to be taken into account when considering the effectiveness of urban counterterrorism measures. The overall aim of this article is to contribute to building better security practices, in addition to contributing methodological reflections in security research.

\section{Methodological approach}

Bearing in mind the vast quantity of resources spent on urban terrorism security during recent decades, the academic literature that deals with the effectiveness of counterterrorism measures is surprisingly small. Thus, the topic is under-researched, compared to its wide application. In order to investigate how to measure the effectiveness of counterterrorism measures from a local perspective, we performed a literature search, looking for articles that dealt with the effectiveness of urban counterterrorism measures. We used search engines such as Google Scholar and Web of Science to find relevant academic articles. We applied the search words, "effectiveness", "effect", "counterterrorism", "terrorism", to look for articles that dealt with the effectiveness of counterterrorism in general and for city planners in particular. Since our search generated a large number of academic articles, we manually went through the articles to select the most relevant ones. While there were a number of articles that dealt with the topic of urban counterterrorism, few dealt with the matter of effectiveness. Consequently, we also included in the sample academic articles that dealt with the effectiveness of counterterrorism measures in general. Furthermore, we also included literature dealing with the effectiveness of risk-reducing measures. In total, 71 articles were selected for analysis. Although this work builds on these academic articles, its aim is not to give a general state of the art of the literature on the effectiveness of counterterrorism measures. This has already been done by other scholars (see for example Lum et al. 2006; Van Um and Pisoiu 2015). Our aim was 
rather to build on the literature, to outline whether the prism of effectiveness is a suitable perspective from a local planner's point of view and to outline characteristics of the phenomenon of terrorism that need to be taken into account when measuring the effectiveness of urban counterterrorism measures. We have chosen to use Norway as the general example in this article, since Norway recently implemented a security law (The National Security Law 2018) that requires effectiveness as the basis of the implementation of counterterrorism measures.

When dealing with the effectiveness of urban counterterrorism measures, it is appropriate to ask: What is the phenomenon the city strives to protect itself from, and how do the characteristics of the phenomenon influence our ability to measure the effectiveness of urban counterterrorism measures? To answer these questions, we analysed the literature, by classifying the characteristics that challenge the evaluation of the effectiveness of counterterrorism into two main categories, dependent on the status of knowledge:

(1) Ontological characteristics concern what terrorism and urban counterterrorism is and its nature (Solberg and Njå 2012). Thus, ontological challenges deal with what is inherent in the empirical phenomenon of terrorism and urban counterterrorism that influences what we can know about the phenomenon. Ontology refers to the phenomena of reality as such, which we might or might not know, thus having phenomenological or factual knowledge or not (Daase and Kessler 2007).

(2) Epistemological characteristics describe the nature of knowledge regarding terrorism and urban counterterrorism measures and how knowledge might be acquired. Subsequently, epistemological challenges concern how knowledge about terrorism and the effectiveness of urban counterterrorism can or cannot be achieved and the limitations that hamper our attempts to obtain such knowledge (Daase and Kessler 2007; Solberg and Njå 2012).

Ontological and epistemological issues are closely interrelated; the nature of terrorism threats and countermeasures influences how knowledge can be acquired regarding these phenomena (Jackson et al. 2009; Jore 2012). The ontological and epistemological challenges regarding measuring the effectiveness of urban counterterrorism measures are summarized in Table 1.

\section{Terrorism and counterterrorism are discursive phenomena}

Military technology and strategy have always played a key role in the urbanization process. Ruling powers have sought to defend their interests by protecting citizens from threats, to ensure loyalty and enhance the feeling of collectiveness, by making a mark on the landscape of cities. What is new in the accentuating trends in security since 11 September 2001 is that security has become descaled, de-territorial and local (Coaffee 2005). Contemporary terrorism is seen as a transnational phenomenon, in which non-state actors seek to cause political change at the national and 
Table 1 Ontological and epistemological challenges regarding measuring the effectiveness of urban counterterrorism measures

\begin{tabular}{|c|c|}
\hline Ontological challenges & Epistemological challenges \\
\hline $\begin{array}{l}\text { Terrorism and counterterrorism } \\
\text { are discursive phenomena }\end{array}$ & $\begin{array}{l}\text { The phenomena are imbued with ambiguities regarding what are } \\
\text { perceived as effective ways to counter the threat }\end{array}$ \\
\hline Transboundary wicked problem & Hard to establish causality and control for third variables \\
\hline Security is a non-event & Difficult to prove a negative \\
\hline Low probability & $\begin{array}{l}\text { Lack of data and hard to establish causality } \\
\text { Data not representable, transferable or suitable for generalizations }\end{array}$ \\
\hline Secrecy & Unpredictability, lack of valid data on countermeasures \\
\hline Rational actors & Substitution effects \\
\hline Malicious intent & Hard to prove malicious intent, false positive \\
\hline Human complexity & $\begin{array}{l}\text { Multi-causal and multi-agency, little knowledge on the rationality of } \\
\text { target selection }\end{array}$ \\
\hline Ultimate goal is political change & $\begin{array}{l}\text { Negative side effects, fear-inducing measures, symbolic values, value } \\
\text { discrepancies }\end{array}$ \\
\hline
\end{tabular}

international levels, by creating a state of fear through illegitimate means. Despite the often international political agendas of terrorism, the current threat of terrorism is perceived to be internal rather than external. This is exemplified by the manifold attacks stemming from home-grown terrorism against multiple European cities in recent years. Thus, security has become a joint responsibility, in which multiple actors, such as the municipality and local police, have a shared obligation. This downscaling of security responsibility has given local actors, such as city planners and municipalities, a critical role in counterterrorism.

Urban counterterrorism measures are a result of terrorism being perceived as a ubiquitous, omnipresent societal threat and of counterterrorism being seen through the lens of the risk management culture that dominates contemporary societies (Ericson 2006; Power 2004). Consequently, as a threat to cities and their citizens, terrorism is a result of a specific discourse on threats and how such threats should be prevented. Just to be clear: this does not mean that terrorism is not a real-world phenomenon causing devastation, suffering and damage to cities worldwide. It most certainly is. However, it is our understanding of terrorist attacks and the associated threats that is the discursive element in the phenomenon of terrorism, because the concept of terrorism is not a neutral word pointing to an objective, independent and neutral ontological phenomenon. The definition of terrorism is contested, its origins are disputed, and counterterrorism measures are highly ambiguous (FischbacherSmith 2016). Thus, the meaning put into the term and how this phenomenon should be managed is the result of discursive meaning making. The discursive element of terrorism is influenced not only by the way the city is perceived to be threatened but also by what countermeasures are considered legitimate to implement. Through the portrayal of terrorism as a threat that is targeting civilians, no one can feel safe from terrorism, and the city has become a vulnerable object under constant threat, where no one can feel safe. This is what is often referred to as exceptionalism: by creating a state of crisis and emergency, extraordinary measures have become ordinary and a 
part of everyday city life (Aradau and Van Munster 2009). The ultimate consequence of this is that city planners and other actors are forced to take precautionary actions against terrorism, in the endeavour to create a more secure society. Subsequently, urban counterterrorism measures are often precaution-based rather than risk- or evidence-based. The discursive element of terrorism and counterterrorism entails that ambiguities that influence the quality of data and what are considered effective and legitimate ways to counter the threat are embedded in the knowledge concerning these phenomena. The discursive element of terrorism entails a challenge to measuring the effectiveness of urban counterterrorism, because the discursive element of terrorism and counterterrorism implies that urban counterterrorism might be a result of the current discourse threatening the actual way of reducing the threat.

\section{The transboundary wicked problem of terrorism}

It is not only the discursive aspect of terrorism that poses a challenge to knowledge on the effectiveness of counterterrorism measures. A city planner facing the dilemma of how and where to implement security interventions also faces a specific type of policy problem, often referred to as a transboundary wicked problem. Terrorism is not only hard to define and dependent on political-historical discourses, moreover, its origins and solutions are unclear and ambiguous, connected with value discrepancies. Terrorism is intractable, in terms of contested knowledge and expertise, contested values and unpredictability, in terms of religious and ideological dimensions and territorial and geopolitical struggles. Additionally, terrorism is intertwined with other wicked issues (such as the refugee crisis and organized crime) and is characterized by disruptive potential, political and public attention, the performative effects of communication, and global organizational and financial infrastructure (Noordegraaf et al. 2017). Consequently, for a municipality facing the dilemma of whether to implement a security measure, terrorism represents a form of a transboundary wicked problem that is not only about a local challenge, interwoven with uncertainty, but also about globally connected events and ambiguity. Terrorists often direct their violence and threats at a large target group, not immediately involved in the political decision-making process that they intend to influence. The larger the target group, the more difficult it is for authorities to anticipate the next attack (Enders and Sandler 1993). What makes terrorism such a wicked problem is the diversity that is present within the various attack scenarios that could materialize and the associated uncertainty of the intensity of attacks, in which terrorists with relatively simple weapons can cause devastation with cascading effects and major political impacts. The potential range of targets that could be attacked and the potential force multipliers that can be found within the urban spaces that could become the scene of an attack are almost unimaginable (Fischbacher-Smith 2016). The diversified threats that could stem from internal or external perpetrators, from single individuals to state sponsored groups, in addition to the broad spectrum of possible preventive efforts, make urban security governance demanding and difficult.

The transboundary wicked dimensions of terrorism entail that to give a simple answer to the question of which urban security measures work-against which 
threats under which circumstances - might not be easy, because establishing causality between intervention and impact is a major challenge for transboundary wicked problems. To establish causality in social sciences, four criteria should be met (David and Sutton 2011). First, covariation should be established, to provide evidence that policy intervention systematically varies with values on the dependent variable. Secondly, it should be verified that it was the intervention that produced that observed change, by establishing the time order. Thirdly, attempts should be made to exclude other possible causes of the observed impact. As a final point, it should be possible to give a plausible theoretical explanation of the policy impact.

Transboundary wicked problems involve major challenges for the evaluation of urban countermeasures' effectiveness, since it is hard to prove causality. Such risk problems cross the boundaries between countries, policy domains, organizations and scientific disciplines. To assess the effectiveness of countermeasures, a researcher must study large networks and numerous interventions on multiple scales, in order to trace the chains of cause and effect. Consequently, in the case of urban terrorism, effectiveness cannot strictly be evaluated, as the phenomenon, its actors and arenas, potential measures and implications are highly ambiguous and fundamentally contested (Noordegraaf et al. 2017). There are many possible causes for increases in the number of terrorist attacks in a certain city, as there are many possible reasons why a city can be the target of a terrorist attack. A decrease in terrorism threats against a city might not be influenced by measures at the city level at all. An alteration in the number of terrorist attacks in one area might also be triggered by political factors in other countries (e.g. that the Islamic State is losing territory in Syria) or the implementation of other interventions (such as measures to prevent the funding of terrorism). Consequently, the transboundary wicked nature of terrorism makes it hard to establish causality and control for third variables.

It is generally agreed that transboundary wicked problems must be fought with various measures on several different scales. As the public administrator, the main planning authority and the owner of land and buildings, the city authorities (or the municipality) have an important cross-sector coordination role in governing urban terrorism security. However, few municipalities in Norway have the competence and capacity to manage the threat of terrorism, given that this is a totally new type of threat to Norwegian society and, thus, also new to the municipality and its local co-actors.

\section{Security is a non-event}

The aim of implementing local counterterrorism measures is to achieve security. However, to measure what causes security might be methodologically impossible, since security can be described as a non-event; security is achieved when no threats materialize. This makes it hard to study security, because, in practical reality, it is only possible to study insecurity-when a threat materializes - and not security. This influences the ability to study the effectiveness of urban security, because making statements about the effectiveness of urban counterterrorism measures will, in most instances, involve the methodological challenge of proving a negative 
(Lindekilde 2012): if preventive counterterrorism measures in a city are effective, nothing happens, the city is safe and secure and not the scene of a terrorist attack.

To prove, a negative is challenging in two different ways. First, it is impossible to empirically prove that a reduced or non-existent terrorist threat is caused by the implemented urban measures or that a terrorist threat never existed against the city in the first place. Secondly, if nothing happens, it is hard to prove that this is the result of the implemented measures and not due to some other form of third variable. Thus, in order to establish causality between intervention and effect, third variables should be controlled for. In reality, this is not possible when the topic is counterterrorism, as the potential influential variables affecting city safety and security are many and interlinked.

\section{Terrorism is a low-probability event}

According to the Norwegian National Security Law (2018), there should be proportionality between security gains and cost-efficiency. Hence, there should be proportionality between the likelihood, cost and security gains. When assessing the effectiveness of security measures through the lens of cost-efficiency, there is a need to assess the probabilities of the occurrence of different urban attack scenarios. Often, when assessing probabilities, historical statistics data are utilized. Statistical data have the advantage that increases and decreases in trends of terrorism can be established. In theory, the effectiveness of counterterrorism measures could be investigated by comparing statistics for implemented security measures with statistical trends in the number of terrorist attacks, the number of fatalities and material damage (Van Dongen 2011). Statistical data may provide valuable information on general and regional trends in the threat landscape. However, it is not possible to carry out this quantitative statistical comparison in practice at a city level because urban terrorism is an extremely low-probability event. Even if statistics exist for global and regional trends in terrorism, it will not, in most instances, be meaningful to utilize these statistics on a city scale. The frequency of terrorism in European cities is so low that, if trends in terrorism were broken down to a city level, the numbers would be so small that it would not be possible to make any valid or reliable claims. To assess the probability of an attack against a Norwegian city will, in most instances, be to assess the probability of an event that has never happened before.

Since statistical data will never be able to provide valuable information about the probability of terrorism at a city level, it is problematic for municipalities in Norway to assess terrorism within the frame of cost-efficiently suggested in the new National Security Law (2018). In most cases, the probability of a terrorist strike is extremely low, meaning that investments in security measures will not pay off in most cases (Akhtar et al. 2010). The low frequency of urban terrorist attacks makes it hard to utilize the language of effectiveness, if effectiveness is understood as proportionality with the likelihood of the threat.

It is hard to demonstrate that urban countermeasures are effective, when the probability of such events is extremely low. However, contemporary urban security governance is not understood within the frame of proportionally. Rather, it is 
the discourse of resilience that dominates urban security. Contemporary cities are considered to be more vulnerable than before, with a range of possible targets and attack scenarios. Furthermore, it is not evident that any threat or warning sign will be evident beforehand. As a consequence, resilience has become an important part of contemporary urban security discourses. Resilience policy is increasingly driven by security concerns and, at the same time, security policy adopts the language of resilience (Coaffee and Fussey 2015). The resilience discourse has thus paved the way for precaution-based urban security, rather than probability- or evidence-based urban security.

\section{Secrecy}

The secret nature of terrorism is grounded in the fact that terrorism is a criminalized activity. For a terrorist plot to be effective, the terrorists must keep a low profile and not reveal their plans. Thus, terrorism threats are secret by nature. This causes challenges to the municipalities that have to decide where to implement measures, without having any concrete knowledge on what kind of attack scenario to protect against. National threat assessments exist, but threat assessments published by the Norwegian Police Security Service (PST) are of a general character, not mentioning specific targets, cities or geographical areas. The result is that the Norwegian authorities have recommended that security measures should be based on value assessments: it is recommended that security measures are directed at targets that have a national security value. However, the trend to attack softer targets and public places causes a challenge for cities in their security governance, since this type of threat is not necessarily connected with the same objects that have traditionally been seen as important to protect, from a national security perspective.

The secret nature of terrorism also influences access to data on the effectiveness of urban security measures. Since terrorists are strategic human beings that can bypass urban security measures, information on implemented measures is most often classified information. Consequently, openly accessible overviews and information concerning implemented security measures do not exist. The classified nature of counterterrorism measures makes it unrealistic to assume that such statistics will ever be made available. The secret nature of security measures also makes it hard to share knowledge on what works and what does not work in different situations. Even if such statistics existed, it would be hard to prove effectiveness by utilizing statistical data, because of the low likelihood of a terrorist attack.

\section{Rational actors}

One of the main challenges in urban security governance is the dynamic risk picture, in which a perpetrator is adaptable and may alter targets and tactics according to the enactment of urban security measures. The rational, calculating aspects of terrorism create a state of fear in the public. Terrorists play on randomness, to keep whole populations in fear, anticipation and disestablishment. They precipitate an urge in 
the population for more certainty, expressed through escalating security measures, as witnessed in cities worldwide. However, because terrorists are capable of adapting their strategy to subvert urban security measures, more uncertainty is induced in the populations (Ericson 2006).

From a city governance perspective, the rational nature of terrorism entails a challenge when making decisions about urban security. Although, in most cases, a perpetrator possesses far fewer resources than the city, the perpetrator only needs to find one vulnerability to exploit. In contrast, the city must attempt to cover all weaknesses in its security system. The consequence of this is that it is impossible to secure all potential targets. Moreover, because of the rational aspect of terrorism, counterterrorism measures are only effective when it comes to a few of the many possible threat manifestations. Vehicle mitigation measures, for example, do nothing to protect against attacks by aircraft or suicide bombers wearing explosive belts (Dalgaard-Nielsen 2017).

Furthermore, since terrorists are rational actors, it also means that, if one target in the city is secured, there is a risk of simply just moving the risk to another target. A well-known problem with reducing the risk of terrorism through target hardening is that, when one target is protected, the risk-reducing effect only applies to that specific target (Cauley and Im 1988; Enders et al. 1990; Landes 1978). This research has demonstrated the so-called substitution effect: the hardening of one target leads to increases in the numbers of attacks on other targets. For example, the installation of metal detectors in airports reduced skyjackings and diplomatic incidents but increased other kinds of hostage attacks (barricade missions, kidnappings) and assassinations. In the long run, embassy fortification decreased barricade missions but increased assassinations (Enders and Sandier 1993). The substitution effect makes it hard to measure the effectiveness of urban counterterrorism measures. From a city planner's perspective, the substitution effect means that, in hardening one target, the risk is simply just moved from one object in the city to another.

\section{Malicious intent}

Security threats such as terrorism are defined by their deliberate, intentional malicious intent (Jore 2017). Terrorists deliberately use violence or threats of violence to obtain a political goal. The malicious intent of the nature of terrorism poses a challenge to assessing the effectiveness of urban counterterrorism measures not only because the perpetrator is strategic and can alter plans but because the malicious intent influences the reliability of data about urban terrorism security effectiveness. Even if we have access to data on incidents where counterterrorism measures have prevented a terrorist attack, it is hard to prove that the perpetrator actually had a malicious intent to cause harm. Such data will encompass the uncertainty of false positives: wrongly identifying a source of harm and acting upon that source unnecessarily (Ericson 2006). An example of this is where a person is stopped at a security screening at the entrance of a public building. If this person is stopped with a weapon such as a knife, it is still hard to prove that he or she had the malicious intent to actually use the knife to carry out a terrorist attack. It might also be the case that this person was carrying the knife for 
protective reasons. This means that, even though it is possible to collect data on when security measures such as screenings or arrests work, it is still hard to know that you have valid and reliable data of a perpetrator truly having malicious intent. This entails that the assessor of the effectiveness of security measures can easily draw conclusions based on false positives and find causalities that do not exist. Consequently, even if data on the effectiveness of terrorism exist, it is hard to prove intentionality.

\section{Human complexity}

"Defence in depth" has for centuries been an essential principle used in urban security. Defence in depth refers to a combination of security measures that both reduce the physical opportunities of a successful attack and increase the chances of an attacker being caught (Smith 2003). The idea behind this principle is that, if an object is made difficult to penetrate by hardening the target, the perpetrator will refrain from attacking this object because the possibility of achieving a successful attack is reduced. Since many protective measures are implemented simultaneously, it is hard to measure the effectiveness of a single intervention. Even if there is a desired effect, it would still be unclear which measure or which combination of measures had brought about the desired effect. Also, it may well be that the beneficial effects of one intervention are drowned out by the negative effects of others (Lindekilde 2012).

Furthermore, the models of defence in depth and target hardening have been criticized by scholars, who claim that the rational choice perspective that lies behind these models is too narrow-minded and completely overlooks the complexity and unpredictability of human action (Van Dongen 2011). It is often claimed that terrorists will maximize the outcome of an attack. Regardless of this often-found claim, this statement does not have empirical support. There are multiple examples of terrorist attacks, in which terrorists could easily have maximized the consequence but, for some reason, chose not to. An example of this is the Norwegian terrorist attack against the Government complex in Oslo in 2011, which was carried out at a time of the day when a small number of employees were present in the building complex. Moreover, terrorists are often conventional in target selection, choosing targets or sectors with a high level of security measures, such as the aviation industry. Very little is known about why some targets are picked over others and how perpetrators reason in this process. In addition, very little is known about how security measures influence the choice of target selection and in what way this is done (Van Dongen 2011). Since little research exists on how terrorists reason when selecting targets, it is hard to evaluate whether urban security measures really are effective or not.

\section{Ultimate goal of terrorism is political change}

The ultimate goal of terrorism is not to destroy material values and infrastructure or to harm the city. Since these perpetrators have political change as their final goal, destroying buildings and critical infrastructure and causing loss of life are not the end 
goal-these actions are rather the means. The vital goal of such perpetrators is to create fear, in order to facilitate political change; consequently, it is abstract values that are under threat from such perpetrators. Examples of such values are trust, democracy and even the existence of society itself. This complicates the matter of assessing the effectiveness of counterterrorism measures because it means that these measures should not infringe the values that they aim to protect. A further complication is that most security measures are directed at protecting material and economic assets, not symbolic values.

Urban security measures, such as surveillance or standoffs, are public goods, whose output is non-rivalrous and non-excludable, in the sense that all citizens benefit from them and there is no practical way to prevent anyone from deriving those benefits. However, security measures are not only a public good. They also have negative side effects. Often these negative side effects are presented in the dichotomy of "freedom versus security", following Benjamin Franklin's famous maxim that those wishing to trade freedom for temporary security deserve neither and shall lose both. However, it can be argued that these categories do not share such a dichotomous relationship. Protecting liberty does not automatically generate insecurity, nor does security necessitate a loss of rights. Moreover, this dichotomy can be seen as rather deterministic, as these strategies may not necessarily provide security (Fussey 2011, p. 86).

Most urban counterterrorism measures involve some form of troublesome tradeoffs that need to be taken into account when assessing the effectiveness of urban security measures. Gebbeken et al. (2012) argue that, since a free democratic society will never accept a surveillance state, passive security measures such as innovative and architecturally attractive buildings and landscape elements are the solution, to avoid fortification of the city. Such measures, however, also require troublesome trade-offs Meyer et al. 2015). They affect the physical landscape, including streets, squares, libraries, shopping malls and government buildings, and they entail values' discrepancy regarding aesthetics, legal and ethical issues, environmental considerations, safety, convenience, cost and social inclusion. To what extent these passive security measures benefit the aims of either openness or security is rarely evident.

Since security measures have negative side effects, these should also be taken into account when considering the effectiveness of urban countermeasures. Some urban security measures are controversial, and, in the end, the city might end up threatening the values it aims to protect. A further complication is that some research also suggests that interventions (e.g. military ones) could increase terrorism in the short run while, in the long run, having little significant effect on levels of terroristic violence; in some instances, such measures could increase the risk of terrorism (Fussey 2011; Lum and Kennedy 2012; Van Dongen 2011). These temporal challenges necessitate that the effectiveness of counterterrorism and the associated negative side effects should also be investigated in a long-term horizon.

\section{Discussions}

City authorities nowadays face an extremely difficult challenge when it comes to protecting the city and its citizens from violent acts of terrorism. On the one hand, cities are peculiarly vulnerable to terrorism. They are highly accessible and include 
a variety of possible targets. The buildings and infrastructure density, combined with crowds of people, offer a wide range of potential attack scenarios. Additionally, gatherings of people not only entail the opportunity for mass-scale attacks but also the prospect of instant communication of the terrorists' message to a broad audience by citizens' use of social media. Subsequently, citizens often expect city authorities to respond to the threat of terrorism with a variety of urban counterterrorism measures, to deter future terrorists' possible targets of opportunity and to ensure that the public is safe and secure. On the other hand, multiple ontological and epistemological knowledge limitations, regarding the threat of urban terrorism and how counterterrorism actually affects this threat, mean that city authorities should refrain from just uncritically implementing urban countermeasures. The nine challenges outlined and discussed in this paper are predominantly related to the lack of relevant data and the difficulties of establishing causality in order to assess the effectiveness of urban counterterrorism measures. However, the last challenge outlined in this article might be the one that is most problematic: urban counterterrorism measures involve negative side effects that threaten values that should not be jeopardized without having any tools to measure effectiveness. Swanstrom (2002, p. 135) argues that 'The main threat to cities comes not from terrorism but from the policy responses to terrorism that undermine the freedom of thought and movement that are the lifeblood of cities'. Thus, regardless of ontological and epistemological limitations to the measurement of the effectiveness of urban counterterrorism measures, there is clearly still a need to carry out such evaluations. In modern democracies, authorities at all levels are expected to be accountable for their use of public resources. The lack of a balance between the implementation and assessment of effectiveness can reflect negatively on them (Lum and Kennedy 2012). Thus, how a municipality or a city chooses to prevent urban terrorism matters not only to security outcomes but also to how citizens view the legitimacy of state actions. Thus, the current decision to descale security, so municipalities must spend large amounts of funds to urban security governance, must be coupled with the responsibility of gauging whether measures are effective, ineffective, or harmful.

Although the aforementioned ontological and epistemological limitations in measuring the effectiveness of counterterrorism measures are challenging, attempts should be made to achieve knowledge on what is effective and "evidence-based" urban counterterrorism. The term "evidence-based" as a descriptor for decisionmaking means that choices to implement interventions, like those that attempt to counter terrorism, are based on scientific and analytical knowledge that rigorously examines their impact and outcomes (Lum and Kennedy 2012, p. 4). This should also be the norm for urban security measures. The problem with evaluating the effectiveness of security measures discussed in this article is not that the measurement of the effectiveness of urban security measures is impossible because of the ontological and epistemological aspects of terrorism and counterterrorism. These should rather be seen as knowledge constraints that need to be taken into account when considering the effectiveness of urban counterterrorism measures. Given these knowledge constraints, it is important that those who carry out the evaluation of effectiveness aim to establish a diverse group of evaluators, so that diverse opinions and perspectives can lay the foundation for optimal decision-making and evaluation. 
In reality, multiple actors at the municipality and city level struggle to make decisions on what measures to implement or not and how to prioritize and select between urban security measures that can also have negative side effects. It might never be possible to fully objectively measure the effectiveness of urban counterterrorism measures. Nevertheless, the Norwegian authorities and other local actors are obliged by the new National Security Law (2018) to perform assessments about the effectiveness of such measures. A few scholars have tried to construct evaluation frameworks for terrorism and radicalization policy and associated countermeasures (Langdalen et al. 2018; Lindekilde 2012; Lum and Kennedy 2012; Meyer et al. 2015; Noordegraaf et al. 2017; Van Dongen 2011). At present, these frameworks are not adapted to be utilized in the context of urban security. However, there are undoubtedly concepts, theories and methods that are transferable, if they are adjusted to an urban security context. This is a topic that further research should address.

\section{Conclusions}

Given that the threat of terrorism is a phenomenon imbued with ambiguity, uncertainty, secrecy and human complexity, in which strategic, calculating-yet unpredictablehuman beings are the ones that pose the threat, there will always be knowledge limitations associated with the threat of terrorism and the ability to measure the effectiveness of urban counterterrorism measures. Urban terrorism transcends the distinctions between cause and effect, local and global problems, fact and impression, dependent on numerous factors, making a comprehensive assessment of effectiveness a challenging task. However, new laws have been proposed that claim that security measures should have security gains and be cost-effective. Furthermore, the public deserves an answer to the essential question: Are counterterrorism measures legitimate and effective? Thus, despite the ontological and epistemological challenges associated with measuring the effectiveness of urban counterterrorism measures, there is still a need to do so. The ontological and epistemological challenges of evaluating the effectiveness of security measures do not entail that the measurement of the effectiveness of urban security measures is impossible. The ontological and epistemological challenges should rather be seen as knowledge constraints that need to be taken into account when considering the effectiveness of urban counterterrorism measures. Given that urban counterterrorism measures influence the urban environment and often infringe civil liberties, such measures should not just be uncritically embraced without having any tools to measure their effectiveness. Without knowledge on what constitutes the effectiveness of urban security measures, the city might end up infringing the same values that it aims to protect, without achieving security.

Open Access This article is distributed under the terms of the Creative Commons Attribution 4.0 International License (http://creativecommons.org/licenses/by/4.0/), which permits unrestricted use, distribution, and reproduction in any medium, provided you give appropriate credit to the original author(s) and the source, provide a link to the Creative Commons license, and indicate if changes were made. 


\section{References}

Akhtar, J., T. Bjørnskau, and K. Veisten. 2010. Assessing security measures reducing terrorist risk: Inverse ex post cost-benefit and cost-effectiveness analyses of Norwegian airports and seaports. Journal of Transportation Security 3: 179-195.

Aradau, C., and R. Van Munster. 2009. Exceptionalism and the 'War on Terror': Criminology meets international relations. The British Journal of Criminology 49 (5): 686-701.

Cauley, J., and E.I. Im. 1988. Intervention policy analysis of skyjackings and other terrorist incidents. The American Economic Review 78 (2): 27-31.

Clarke, R. 2009. Situational crime prevention. In Handbook on crime and deviance, ed. M.D. Krohn, A.J. Lizotte, and G.P. Hall. New York: Springer.

Coaffee, J. 2005. Urban renaissance in the age of terrorism. International Journal of Urban and Regional Research 29 (2): 447-454.

Coaffee, J. 2010. Protecting vulnerable cities from terrorism. International Affairs 86 (4): 939-954.

Coaffee, J., and P. Fussey. 2015. Constructing resilience through security and surveillance: The politics, practices and tensions of security-driven resilience. Security Dialogue 46 (1): 86-105.

Daase, C., and O. Kessler. 2007. Knowns and unknowns in the 'War on Terror': Uncertainty and the political construction of danger. Security Dialogue 38 (4): 411-434.

Dalgaard-Nielsen, A. 2017. Organizational resilience in national security bureaucracies: Realistic and practicable? Journal of Contingencies and Crisis Management 25 (4): 341-349.

David, M., and C.D. Sutton. 2011. Social research. An introduction, 2nd ed. New Delhi: Sage.

Dillon, R.L., R.M. Liebe, and T. Bestafka. 2009. Risk-based decision making for terrorism applications. Risk Analysis 29 (3): 321-335.

Enders, W., and T. Sandier. 1993. The effectiveness of antiterrorism policies: A vector-autoregressionintervention analysis. American Political Science Review 78: 829-844.

Enders, W., T. Sandier, and J. Cauley. 1990. UN conventions, technology and retaliation in the fight against terrorism: An econometric evaluation. Terrorism and Political Violence 2 (1): 83-105.

Ericson, R. 2006. Ten uncertainties of risk-management approaches to security. Canadian Journal of Criminology and Criminal Justice 48 (3): 345-356.

Fischbacher-Smith, D. 2016. Framing the UK's counter-terrorism policy within the context of a wicked problem. Public Money and Management 36 (6): 399-408.

Fussey, P. 2011. An economy of choice? Terrorist decision-making and criminological rational choice theories reconsidered. Security Journal 24 (1): 85-99.

Gebbeken, N., T. Döge, and M. Larcher. 2012. Safety and security of urban areas through innovative architectural and structural concepts. In Future security, vol 318. Communications in computer and information science, ed. N. Aschenbruck, P. Martini, M. Meier, and J. Tölle, 153-164. Berlin: Springer.

Graham, S. 2012. When life itself is war. International Journal of Urban and Regional Research 36 (1): 136-155.

Hemmingby, C. 2017. Militant Islamists' targeting preferences in Europe. Perspectives on Terrorism 11 (5): $25-41$.

Jackson, R., M.B. Smyth, and J. Gunning (eds.). 2009. Critical terrorism studies: A new research agenda. London: Routledge.

Jore, S.H. 2012. Counterterrorism as risk management strategies. PhD thesis no. 178, Faculty of Science and Technology, University of Stavanger, Norway.

Jore, S.H. 2017. The conceptual and scientific demarcation of security in contrast to safety. European Journal of Security Research. https://doi.org/10.1007/s41125-017-0021-9.

Landes, W.M. 1978. An economic study of US aircraft hijacking, 1961-1976. Journal of Law and Economics 21: 1-31.

Langdalen, H., E. Abrahamsen, J. Selvik, and S.H. Jore. 2018. A discussion on socio-economic profitability as a prerequisite for investments in security measures. Cambridge: The Business Review.

Lindekilde, L. 2012. Value for money? Problems of impact assessment of counter-radicalization policies on end target groups: The case of Denmark. European Journal on Criminal Policy and Research 18 (4): 385-402.

Lum, C., and L.W. Kennedy. 2012. Evidence-based counterterrorism policy. In: Evidence-based counterterrorism policy, 3-9. New York: Springer 
Lum, C., L.W. Kennedy, and A.J. Sherley. 2006. The Effectiveness of counter-terrorism strategies: Campbell systematic review summary. Campbell Systematic Reviews 2 (1): 1-50.

Meyer, S., S.H. Jore, and K. Johansen. 2015. Troublesome trade-offs: Balancing urban activities and values when securing a city-centre governmental quarter. City, Territory and Architecture 2: 8.

National Security Law [Lov om nasjonal sikkerhet]. 2018. https://lovdata.no/dokument/NL/lov/2018-0601-24. Accessed 15 Aug 2018 (only in Norwegian).

Noordegraaf, M., S. Douglas, A. Bos, and W. Klem. 2017. How to evaluate the governance of transboundary problems? Assessing a national counterterrorism strategy. Evaluation 23 (4): 389-406.

NOU (Official Norwegian Reports). 2016. No. 19. Samhandling for sikkerhet - Beskyttelse av grunnleggende samfunnsfunksjoner i en omskiftelig tid (only in Norwegian).

NSM - National Security Authority, the Police Direktorat, and the Security Police. 2015. Terror security. A guide in security and preparedness measures against intentional unwanted actions. [TERRORSIKRING. En veiledning i sikrings- og beredskapstiltak mot tilsiktede uønskede handlinger]. https://www.nsm.stat.no/globalassets/dokumenter/veiledninger/veileder_terrorsikring_2015_enkel ts_final.pdf. Accessed 15 Aug 2018 (only in Norwegian)

Office, U. S. G. A. 2005. GAO report to congressional requesters, Risk management further refinement needed to assess risks and prioritize protective measures at ports and other critical infrastructure.

Power, M. 2004. The risk management of everything: Rethinking the politics of uncertainty. London: Demos.

Smith, C.L. 2003. Understanding concepts in the defence in depth strategy. In: Security technology, 2003. Proceedings. IEEE 37th annual 2003 international carnahan conference, 8-16. IEEE.

Solberg, Ø., and O. Njå. 2012. Reflections on the ontological status of risk. Journal of Risk Research 15 (9): 1201-1215.

Stewart, M.G. 2008. Cost effectiveness of risk mitigation strategies for protection of buildings against terrorist attack. Journal of Performance of Constructed Facilities 22 (2): 115-120.

Stewart, M.G., and J. Mueller. 2013. Terrorism risks and cost-benefit analysis of aviation security. Risk Analysis 33 (5): 893-908.

Swanstrom, T. 2002. Are fear and urbanism at war? Urban Affairs Review 38 (1): 135-140.

Van Dongen, T.W. 2011. Break it down: An alternative approach to measuring effectiveness in counterterrorism. Journal of Applied Security Research 6 (3): 357-371.

Van Um, E., and D. Pisoiu. 2015. Dealing with uncertainty: The illusion of knowledge in the study of counterterrorism effectiveness. Critical Studies on Terrorism 8 (2): 229-245.

Publisher's Note Springer Nature remains neutral with regard to jurisdictional claims in published maps and institutional affiliations. 